\title{
Experimental tests of sheeting made of sandwich panels acting as a diaphragm
}

\author{
M. Górski \\ Rzeszów University of Technology, Rzeszów, Poland
}

\begin{abstract}
Results of experimental tests of a part of sheeting made of sandwich panels are shown in this paper. In-plane stiffness and resistance of the sheeting have been determined and compared with the values achieved from formulas available in literature. The results show, that sheeting made of sandwich panels has noticeable in-plane parameters and is worth to be included in designing as an improvement of elements stability.
\end{abstract}

\section{INTRODUCTION}

The Eurocode EN 1993-1-3 specifies 3 structural classes differing from each other in the way of including the cooperation between structure and sheeting in design:

- Structural Class 1: Sheeting is included in the calculations of the overall strength and stability of a structure;

- Structural Class 2: Sheeting is included in the calculations of strength and stability of individual structural members;

- Structural Class 3: Sheeting is considered as an element that only transfers loads to the structure.

In the conventional designing of steel roofs, sandwich panels are considered as noncooperating sheeting due to rather thin steel plates used (ca. $0.5 \mathrm{~mm}$ ) and lack of seam fasteners between internal faces of each sandwich panels, which induces a low-effective way of transferring load in the sheeting plane, because each panel must act independently, as shown in Figure 1.

Nevertheless, some research is currently available, e.g. (Baehre \& Ladwein 1994, Dürr et al. 2007, Misiek et al. 2010, Dürr et al. 2011, Käpplein \& Misiek 2011, Georgescu \& Ungureanu 2012) showing noticeable stiffness of sheeting made of sandwich panels and the possibility of including them in the designing in Structural Class 2. Moreover even if the stiffness of sheeting is relatively small, it results in evident increasing of the purlin stability (Górski \& Kozłowski 2021).

This paper presents the results of own experimental tests of the part of sheeting made by sandwich panels in the context of cooperation with steel structure including designing in Structural Class 2.

\section{TEST STANDING}

The tested structure consist of a pair of girders with distance $5.4 \mathrm{~m}$ made of horizontalsituated hot-rolled channel UPN160, 3 purlins arranged at a distance of $2.9 \mathrm{~m}$, made of hot-rolled I-beam IPE160 and five sandwich panels Balextherm PU-PIR-W-ST 80.1100

DOI: $10.1201 / 9781003132134-25$ 


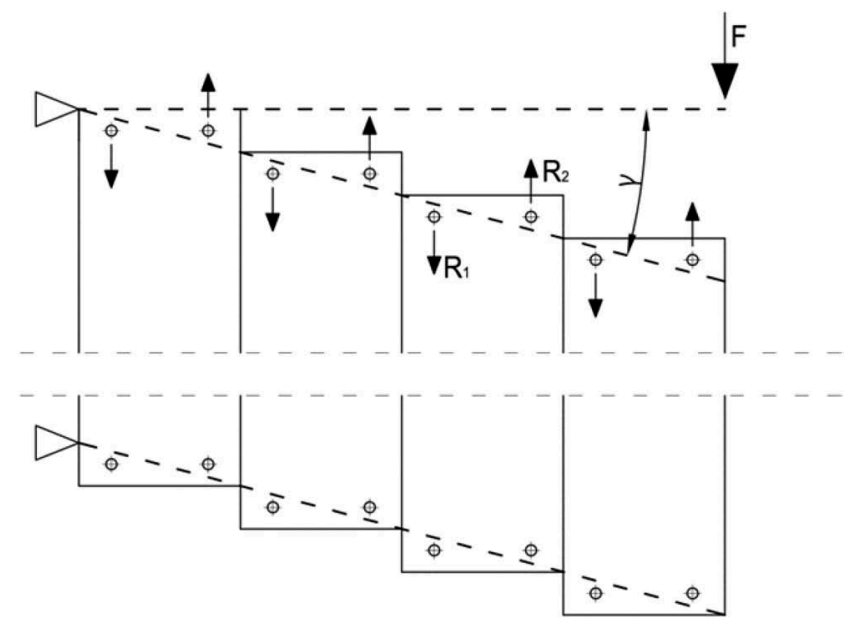

Figure 1. Assumption of transferring load $\mathrm{F}$ acting in sheeting plane by sandwich panels.

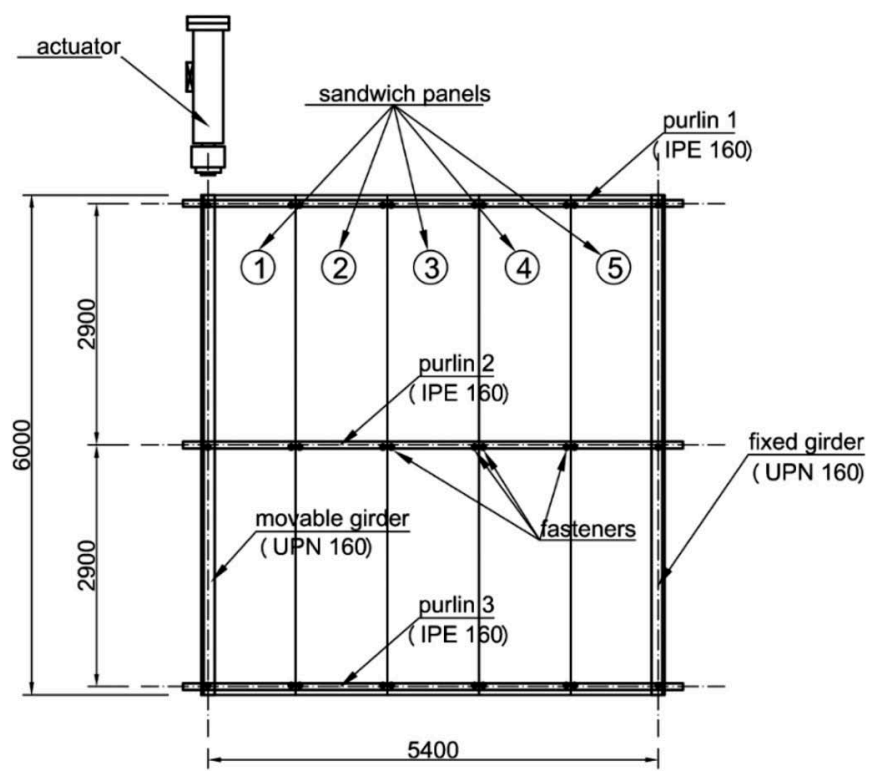

Figure 2. The schema of test standing.

with face sheets made of steel S320GD and thickness $0.5 \mathrm{~mm}$. The schema of test standing is shown in Figure 2.

The connections between purlin and girder were made of bended plates with thickness $6 \mathrm{~mm}$, additionally stiffened by welded diagonal ribs and bolted with structure by 2 pairs of bolts M12 (Figure 3). Each sandwich panel was connected with each purlin using 2 self-drilling screws $5.5 / 6.3 \mathrm{~mm}$ arranged in distance $50 \mathrm{~mm}$ from the panels edges (1000 $\mathrm{mm}$ from each other).

One of the girder was fully fixed. The second one has been placed on round rods to ensure free movement in the axis of girder. To prevent lateral movement of this girder, four vertical CHS profiles were used (Figure 4). 


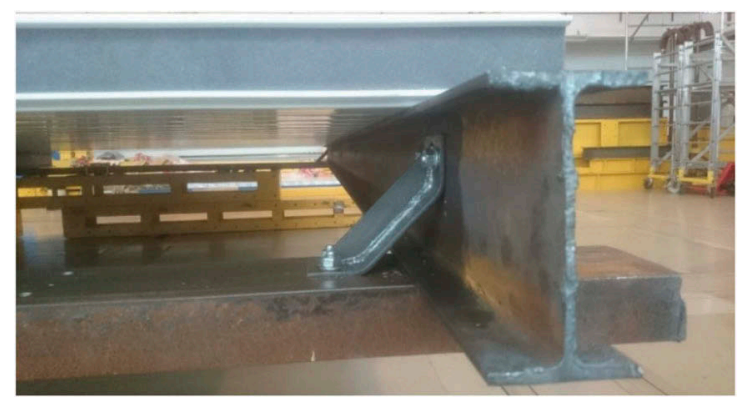

Figure 3. The view on connection between purlin and girder.

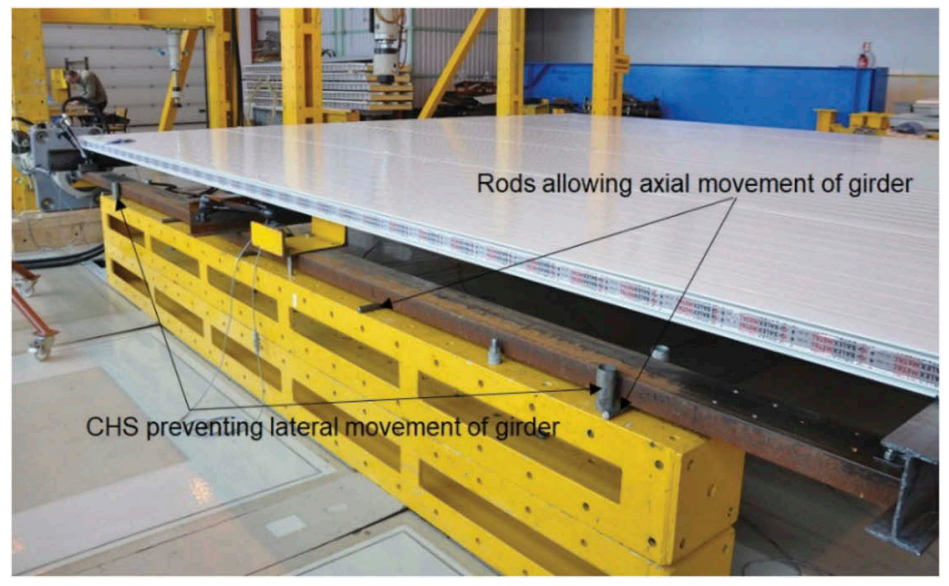

Figure 4. The schema of test standing.

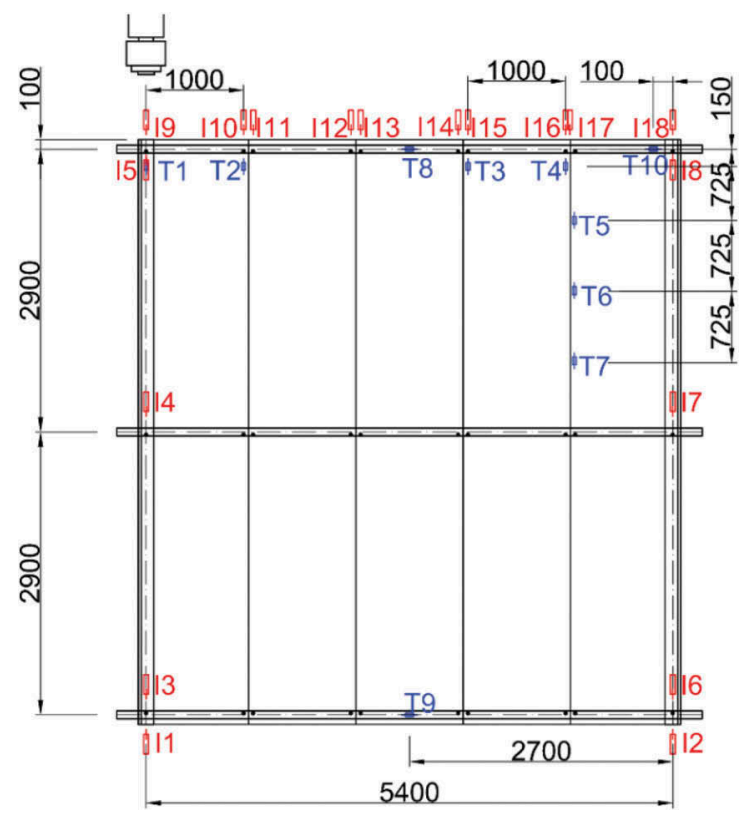

Figure 5. The arrangement of sensors and strain gauges during tests. 
The load was applied using horizontal-situated actuator Instron Schenck $630 \mathrm{kN}$ directly to the movable girder in 3 applications: $0-2.0 \mathrm{kN}, 0-4.0 \mathrm{kN}$ and $0-$ value of in-plane resistance.

The displacement of 18 selected points has been measured using inductive displacement sensors: movable girder relative to the floor (I1), fixed girder relative to the floor (I2), purlins in the place of connections with girders relative to the girders (I3 - I8) and each of sandwich panels in two points arranged at a distance $5 \mathrm{~cm}$ from their side edges relative to the purlin 1 (I9 - I18). In addition 10 foil strain gauges were used to measure the strains: on bottom face of sandwich panel number 1 and 4 in the distance $150 \mathrm{~mm}$ from the axis of the purlin $1(\mathrm{~T} 1-\mathrm{T} 4)$, on the bottom face of sandwich panel number 5 along its edge in contact with panel number 4 (T5 - T7), on the top flanges of side purlins in the middle of their spans (T8 and T9) and on the top flange of the purlin 1 in the distance $100 \mathrm{~mm}$ from the axis of the fixed girder (T10). The arrangement of the displacement sensors and strain gauges is shown in Figure 5.

\section{RESULTS}

The results of the test have been presented in two forms: of force - displacement relationship for data obtained from displacement sensors and of stress - force relationship for data obtained from strain gauges. Stress has been calculated by multiplying the values of strain and the Young modulus, which has been assumed as $210 \mathrm{GPa}$. Figure 6 shows the results from sensor I1 which are crucial to determine the global parameters of the sheeting. Figures $7-8$ shows the results from displacement sensors and Figures $9-10$ the results from strain gauges. The view of the deformed shape of sheeting is shown in Figure 11a and the hole elongation is presented in Figure 11b.

The results have proven the correctness of theoretical model shown in Figure 1. The forces in the connections located on the one side of the panels had opposite directions to the forces on the second side. The transverse edge of the sheeting, straight before test, became visibly serrated. The in-plane behavior of sheeting is nonlinear due to hole elongation in the connections. The sheeting resistance according to the shape of approximation curve equals $6.2 \mathrm{kN}$. The in-plane stiffness of sheeting can be calculated using formula (1). Table 1 shows the values of in-plane stiffness of tested sheeting obtained for various range of data.

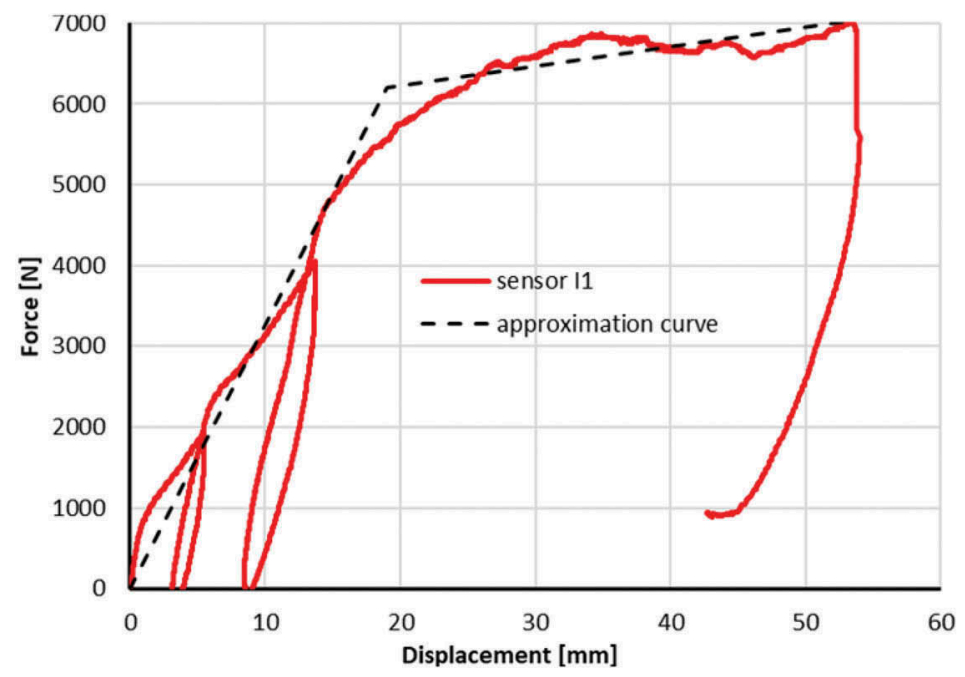

Figure 6. Dependence force - displacement for sensor I1. 
Sensors 13 - 18 (purlins supports)

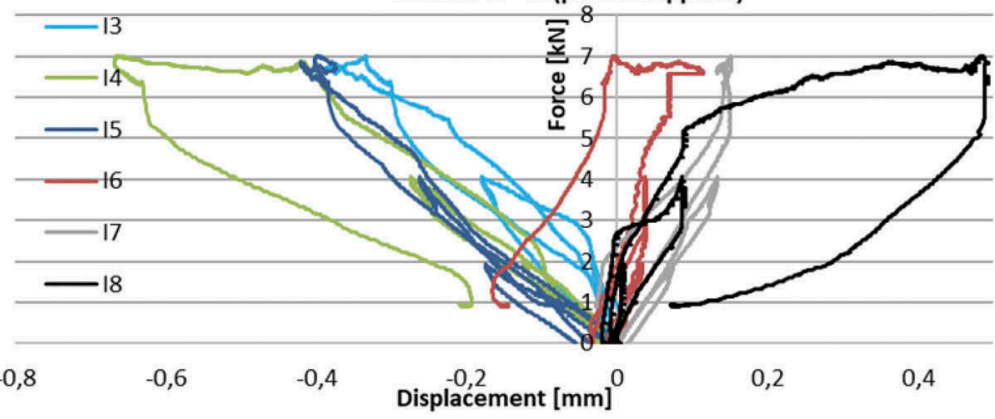

Figure 7. Dependence force - displacement for sensors I3 - I8.

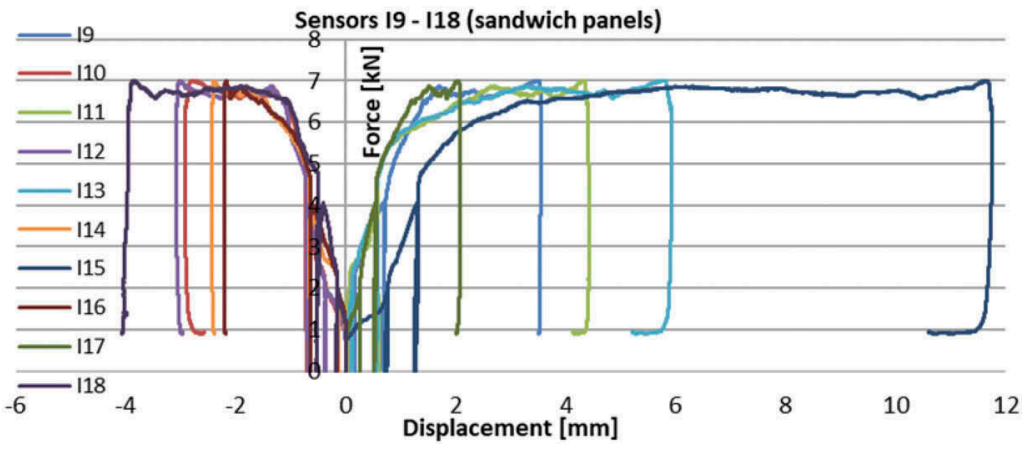

Figure 8. Dependence force - displacement for sensors I9 - I18.

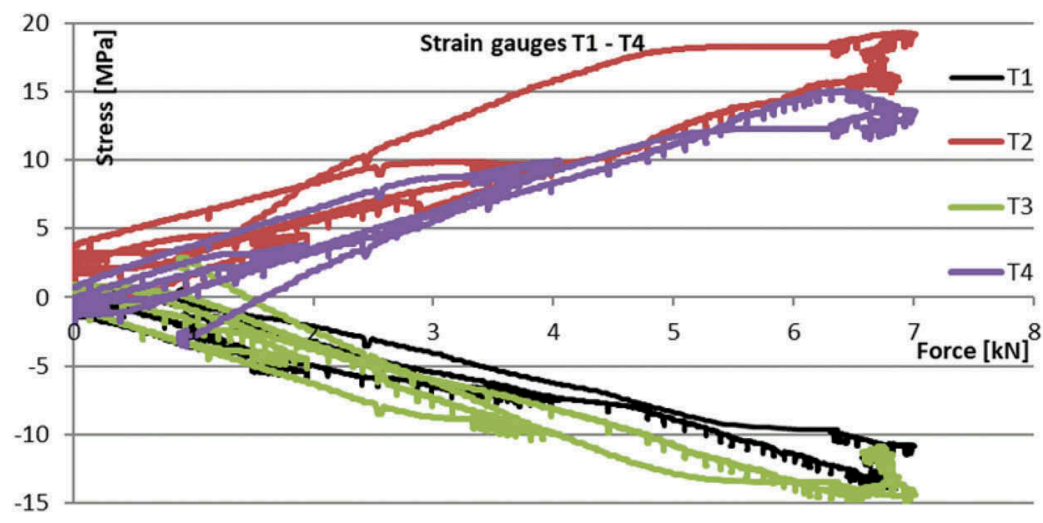

Figure 9. Dependence stress - force for strain gauges T1 - T4. 


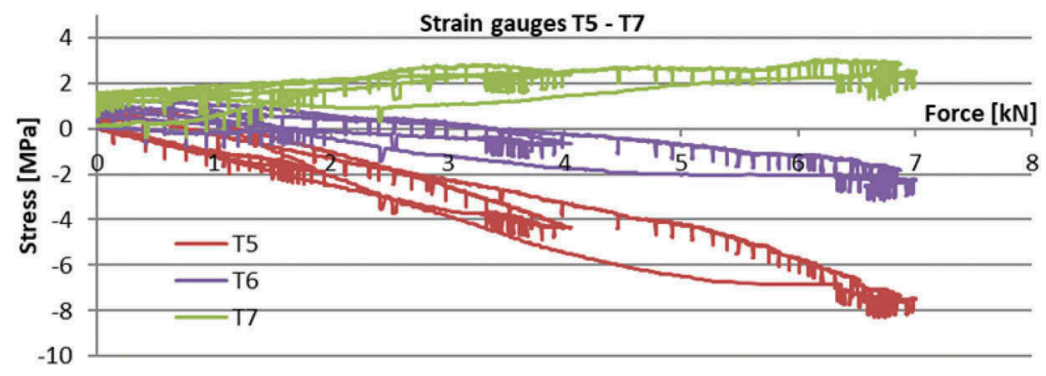

Figure 10. Dependence stress - force for strain gauges T5 - T7.

a)

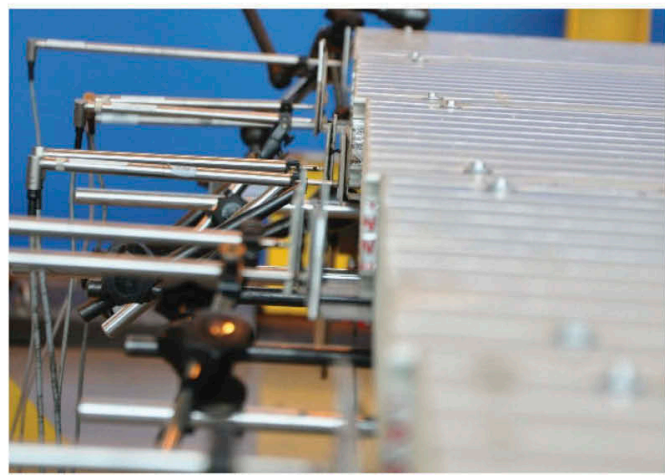

b)

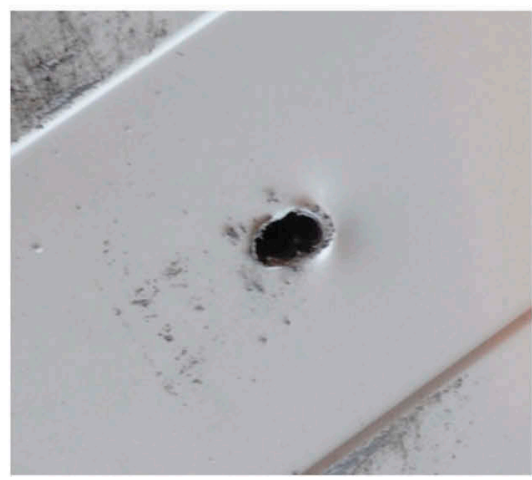

Figure 11. View of the structure after test: a) the transverse edge of the sheeting, b) the hole elongation after removing fastener.

Table 1. Values of in-plane stiffness of tested sheeting for various range of data.

\begin{tabular}{ll}
\hline & Stiffness per one purlin \\
\cline { 2 - 2 } Considered range of data & $\mathrm{kN} / \mathrm{m} / \mathrm{m}$ \\
\hline Beginning of the first force application $(0-0.8 \mathrm{kN})$ & 2052 \\
Beginning of the second force application $(0-2.0 \mathrm{kN})$ & 1494 \\
Beginning of the third force application $(0-4.5 \mathrm{kN})$ & 1368 \\
Approximation curve $(0-6.2 \mathrm{kN})$ & 587 \\
\hline
\end{tabular}

$$
S=\frac{F \cdot a}{\Delta \cdot n}
$$

where $F=$ applied force; $a=$ width of sheeting; $\Delta=$ displacement according to Figure 12 and $n=$ number of purlins.

According to formulas given in ECCS (2013), the in-plane stiffness of such sheeting made by sandwich panels equals $1200 \mathrm{kN} / \mathrm{m} / \mathrm{m}$. Although the initial stiffness of tested sheeting exceed this value, nonetheless the mean stiffness is noticeably smaller. 


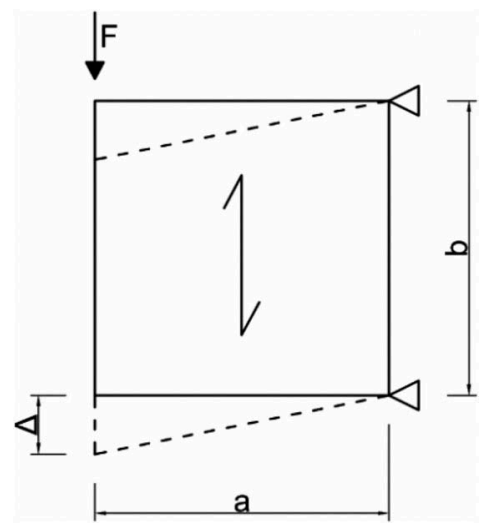

Figure 12. The model to calculation the in-plane stiffness of sheeting.

\section{CONCLUSIONS}

Performed tests proved that the sheeting made of sandwich panels has noticeable in-plane stiffness, despite a low-effective way of transferring loads. The sheeting may be included in designing of structure in Structural Class 2, results in improvement of elements stability. However, the carefulness must be made because of low values of the sheeting in-plane resistance, which can lead to holes elongation and decreasing the overall sheeting parameters.

\section{REFERENCES}

Baehre, R., Ladwein, Th. 1994. Diaphragm action of sandwich panels. Journal of Constructional Steel Research 31: 305-316.

Dürr, M., Misiek, Th., Saal, H. 2011. The torsional restraint of sandwich panels to resist the lateral torsional buckling of beams. Steel Construction - design and research 4: 251-258.

Dürr, M., Podleschny, R., Saal, H. 2007. Investigation of the torsional restraint of sandwich panels against lateral torsional buckling of beams) Stahlbau 76: 401-407.

ECCS 2013. European Recommendations On The Stabilization Of Steel Structures By Sandwich Panels.

EN 1993-1-3 (2006) Eurocode 3: Design of steel structures - Part 1-3: General rules - Supplementary rules for cold-formed members and sheeting.

Georgescu M., Ungureanu V. 2012. Stabilisation of continous Z-purlins by sandwich panels: Full scale experimental approach. The 6th International Conference on Coupled Instabilities in Metal Structures, Glasgow.

Górski M., Kozłowski A. 2021. Behaviour of hot-rolled purlins connected with sandwich panels. Archives of Civil Engineering 67/1 (in printing)

Käpplein, S., Misiek, Th. 2011. Stabilisation of beams by sandwich panels. EASIE report D3.3 - part 1,2 and 3.

Misiek, Th., Käpplein, S., Dürr, M., Saal, H. 2010. Stabilisation of purlins by sandwich panels - new regulations and recent research results., Proceedings of 18th CIB World Congress Salford. 